\title{
Trafficking in Women and Girls for Sexual Exploitation Is a Crime and Human Rights Violation
}

\author{
Nguyen Thi Hoai Duc \\ The Institute for Reproductive and Family Health (RaFH), Hanoi 844, Vietnam
}

\begin{abstract}
Abtract: Although the Vietnamese Government has many policies and laws to protect women's rights and prevent violence against women, trafficking in women and children for sexual exploitation is increasing rapidly and complexly in Vietnam. Girls and young women from many provinces in Vietnam are trafficked daily to China through border gate of China of Lao Cai, Lang Son, Cao Bang and Quang Ninh in the North, An Giang, Kien Giang, Dong Thap and Tay Ninh in the South. Many new chains of trafficking women and girls have been established and they are difficult to indentify therefore polices and border guards cannot control all of them. Women, girls and teenagers are trafficked victims who are poor, jobless, low education and ethnic minorities. Trafficked women and girls are sent directly to foreign men or brothels, karaokes, bars, where they are often suffered from post traumatic stress. They experience long-term torture caused by traffickers such as multiple gang rape, severe punishment like beating and starve which results in long-term health problems as physical injuries, psychological and mental disorder, even almost of them have risk of different kinds of diseases, STDs (sexual transmitted diseases), HIV/AIDS (human immunodeficiency virus/acquired immunodeficiency syndrome). The situation of trafficking in women and girls are seriously damaging women health and human rights. Therefore, the intervention anti-trafficking in women and girls for sexual exploitation is not only in one country but also around the world. Anti trafficking in person is actually a difficult action because of poverty, sex demand, gender in equality and violate human rights everywhere. We should getting together to make more efforts to intervene anti trafficking in person. The contributions of civil society network and community people are crucial and important because they are aware who are traffickers and who are trafficked victims.
\end{abstract}

Key words: Trafficking in person, human rights, women human rights.

\section{Introduction}

Despite the substantial progress of women human rights movement around the world, the trafficking in women and girls in all form continue unabated. Until now, there have been many international anti-trafficking in person programs, but trafficking in person occurs every day and becomes more serious in the world. The existing of poverty, gender inequality, human rights awareness in low and developing countries results in trafficking in person increasing dramatically in recent years. Trafficking in women and girls is a problem of violation of fundamental of women human rights and it is a type of crime that we need to struggle against in person in our efforts.

According the informal reports by IOM

Corresponding author: Nguyen Thi Hoai Duc, Ph.D., research field: women health and rights. E-mail: rafh@hn.vnn.vn.
(International Organization of Migration), there are annually one million women and children being trafficking all over the world. Because human trafficking brings traffickers a huge profit every year, many chains of traffickers have been established complexly and it has been an uncontrollable issue. The phenomenon of trafficking in person has been happening so sophisticatedly in Europe, Australia and North America, especially in Mekong sub-region such as Taiwan, Macau, Hong Kong, Korea, Japan, Malaysia and Singapore. There are estimated around 30 millions trafficked women in Asia in the last several decades [1]. In recent years, trafficking in women and girls for sexual exploitation has been regarded as a form of gender violence and great public concern in Vietnam.

Along with socio-economic development, the phenomenon of trafficking in person in particular 
women and children has been rapidly increasing since the 1990s in Vietnam, especially in Northern border with China and Southern border with Cambodia and Lao, which are places of trading, tourism, business, hot-pot of smuggling, illegal immigration.

Statistics on victims were limited to report. In 2007, the authorities only reported 422 victims who finally returned from China through official road. In fact, the number of women who were suspected of being trafficked to China is much higher. There were about 22,000 women and children trafficked. Girls and young women from many provinces in Vietnam are trafficked to China through border gate of China of Lao Cai, Lang Son, Cao Bang and Quang Ninh in the North, An Giang, Kien Giang, Dong Thap and Tay Ninh in the South [2].

Trafficking chains and routes are formed across the country and border with a lot of sophisticated and uncontrollable tricks. Traffickers are often victims' acquaintances, relatives, friends or a transnational and organized crime or even ex-victims. Normally, one trafficker goes across the border to find out "receivers", then comes back to Viet Nam to trick women or girls. Trafficker groups organize network: includes recruitment, procurement stealthily and transportation office. They often position themselves as employment agents to recruit or abduct them for the purpose of sexual exploitation, inducing parents/relatives to part with a woman/girl, but then traffic them to work in prostitution, domestic servitude, or a commercial enterprise. Other forms of exploitation: kidnapping, coercion and deception are often happening. Traffickers go to remote villages and hamlets, understand their targets and then deceive them with wishes for a well-paid job, marriage, educational opportunities or a better life. They also make use of internet, cell phones to set up selling and buying routes for sexual exploitation via internet, cell phones and hold travels across the border. Traffickers make also use of Open Policy of Viet Nam, visit attractive destinations to co-do business and then finally trick people under labor export, children adoption or marriage with foreigner men. Actually, they are organized crime working illegal, secretly and underhandedly [2-6].

Trafficked victims are often women, girls and teenagers. In particular, ethnic women and girls who are poor, unemployed, suffered from gender discrimination and violence with low living standards and education level are more likely to be trafficked. Trafficking in women and girls for sexual exploitation, forced and violent sexual intercourse are factors of injuring women genital organs, which leads to STDs (sexual transmitted diseases) and HIV/AIDS transmission. Recently, the potential increasing of teen-aged girls are being trafficked for sexual exploitation purpose. They are forcibly abducted from their home, surroundings, domestically or internationally then sold to brothels, bars, karaoke and restaurants for hidden prostitution. Trafficked victims are often suffered from post traumatic stress. They experience long-term torture caused by traffickers such as multiple gang rape, severe punishment like beating and starve which results in long-term health problems as physical injuries, psychological and mental disorder. Victims often experience sexual violence because of clients' different behaviors such as nonuse of condoms or abnormal sexual behaviors that easily cause trauma to genital and other body parts. However, in order to survive, victims still have to obey traffickers. Trafficking in women and girls for sexual exploitation has brought not only violation of fundamental human rights but also increased risk of different kinds of diseases, STDs, HIV/AIDS and damages women/girls' lives. It also affects the social well-being of victims who are stigmatized and ostracized by their families and communities. It affects human reputation and values. Victims often feel self-stigmatized which makes them hard to re-integrate in communities [2-6].

According the study of RaFH in 2007-2008 in Lao Cai and Lang Son, there were 298 women and girls trafficked, 312 were suspected to be trafficked and 461 got married to foreigners [2]. 


\section{Materials and Methods}

\subsection{Quantitative Method}

The Quantitative questionnaire was designed to identify knowledge and attitude of the local authorities and communities on the issues of trafficking in women and children, sexual violence and HIV/AIDS prevention. By using these questionnaires, research team also can understand attitude of community towards victims of trafficking, sexual violence and people living with HIV/AIDS. There were 199 representatives aged from 20-60 years. Basically, selected samples were representative in the two project districts. The research team tried to balance the sex of respondents, but men were more likely out of their towns, then they accounted for one third of the samples.

\subsection{Qualitative Method}

The research team conducted IDI (in-depth interviews) local authorities at all levels, repatriated victims, victims of sexual violence and HIV/AIDS infected people to collect information related to trafficking in women and children situation, sexual violence, and HIV/AIDS infection. The IDI guides was carefully prepared to explore the awareness of the local authorities and communities, vulnerable groups on correlation between trafficking in women and children, sexual violence and risk of HIV/AIDS infection.

The research team conducted IDI with 28 persons including: 4 persons from provincial women's union (2 people/province); 2 Provincial border guards (1 people/province); 2 persons from provincial Centre for HIV/AIDS prevention; 2 persons from provincial department of social evils prevention; 6 persons at restaurants and hotels in 2 provinces; 6 repatriated women and HIV infected women; 4 female sex workers; 2 persons of high risk groups of trafficking in Lao Cai province ( 2 pupils at 11 th grade who usually travel to China).

\subsection{Observation Method}

Hotels and guesthouses were observed in order to design project intervention into these guesthouses/hotels/karaoke bars. Researchers conducted observation of these locations and took note during their observation to check whether clients of these guesthouses were provided with free-of-charge condoms, IEC materials.

Researchers also observed and took note of commercial sex work in public areas such as in the parks and on the street during the night. Observation was done in cafés in $\mathrm{Km}$ 6th on the way to Sapa. Researcher team also observed and conducted IDIs with people living around these café about commercial sex in that area.

\subsection{Secondary Data}

Data collection and analysis were done on available information including the HIV/AIDS infection in the two project provinces and communes. Reports, in a three year period to the date of research, on trafficking in women and children; written document and policies related to the prevention of trafficking in women and children were reviewed. Data sources included people's committee, public security, health system from provincial to commune levels; from border officer, provincial HIV/AIDS control bureau, provincial social evil control bureau.

\section{Results and Discussion}

Lao Cai is a poor Northern borber province bordering Yunnan province, China. There are two international border gates and many trails leading to China. People usually go back and forth for business and trading between the two countries and it is a province in the process of urbanization. Lao Cai City shares the border with Haikou district, Junnan province, China where there are many brothels, Vietnamese owned hotels that receive female victims trafficked through the Lao Cai border gate (Fig. 1). Lao Cai international border gates are located in 5 wards of the City. This is also a place where smuggling, trafficking in persons, goods exchange, and tourism occur in complex 


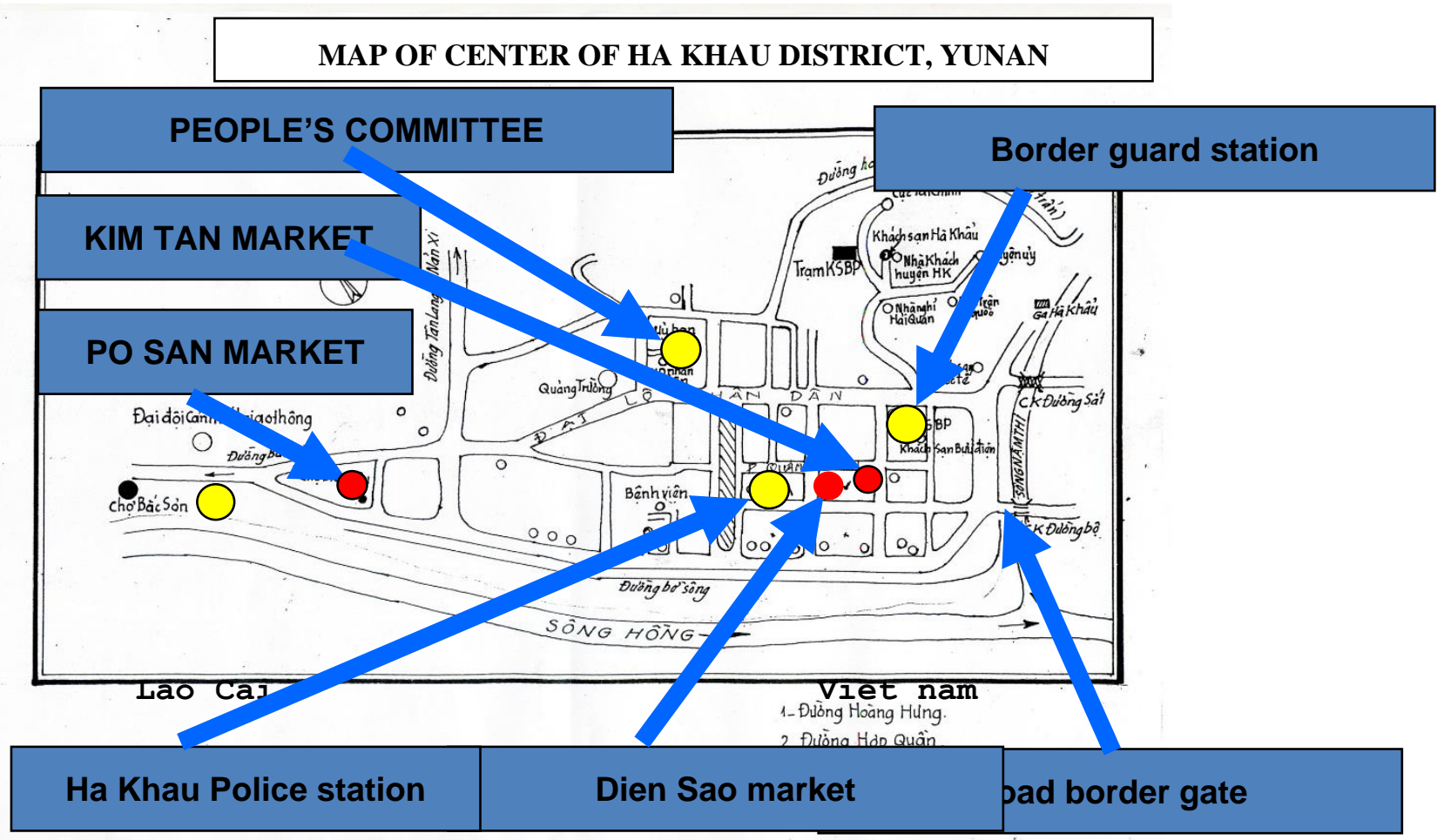

Fig. 1 Map of Center of Ha Khau District, Yunan Province.

circumstances every day.

Lang Son is a northern border province between China and Vietnam with its border line of $253 \mathrm{~km}$ long through 21 communes, towns of five border districts. There are two international border gates, four national gates and seven Vietnam-China markets in Lang Son. In October 2008, the Government has issued the decision on establishment of the Dong Dang-Lang Son border gate economic zone with the total square of about $394 \mathrm{~km}^{2}$ including a part of Lang Son city, Cao Loc, Van Lang, Chi Lang, and Van Quan districts. Dong Dang-Lang Son border gate economic zone has become "Northern key quadrangle" including Lang Son, Hanoi, Hai phong and Quang Ninh. Therefore, many women and girls were trafficked through Lang Son province.

According to the Provincial Bureau of Social Evil prevention, amongst trafficked women and children, $63.5 \%$ were female at the age of 16 to 30 years. In the first 9 months of 2008, 160 traffickers detected, 193 victims are women and children, an increasing of $63 \%$ in comparison with the same period of 2007 , but only
90 victims were supported. Ethnic minorities account for $75 \%$ in the total of trafficked victims, there was $82 \%$ of poor ethnic minority victims in 2007-2008 (Table 1); $21 \%$ of them was illiterate, $78 \%$ of them were at primary and junior secondary level, and $1 \%$ high school level; $100 \%$ of the trafficked women and girls are infected with STDs and some of them are HIV positive. Most of them have psychiatric disorder.

$61 \%$ of restaurants, bars, karaokes in Lao Cai city has hidden prostitutes. $61 \%$ get married at adolescence at the age of 13-17 years. In Hai Khau district, Yunan Province, China, border with Lao Cai province, there are 177 brothels where 500-600 girls are Vietnamese trafficked victims. Trafficked victims experience from both physical and spiritual suffering. Any resistance is usually treated with threats, beating even rape till their acceptance for prostitution. Being trapped in strange places, they rarely have a chance for escape. Trafficked women and girls are also forced into numerous sexual intercourse - they have to serve many men a day, in brothels or to serve in receiving families with 5-7 men in one family. 
Table 1 Repatriated women by ethnic minorities.

\begin{tabular}{llll}
\hline No. & Ethnic & Quantity & Rate $(\%)$ \\
\hline 1 & H'Mong & $59 / 186$ & 31.7 \\
2 & Dao & $36 / 186$ & 19.4 \\
3 & Tay & $30 / 186$ & 16.1 \\
4 & Day & $8 / 186$ & 4.3 \\
5 & Nung & $5 / 186$ & 2.7 \\
6 & Phu La & $5 / 186$ & 2.7 \\
7 & Thai & $3 / 186$ & 1.6 \\
8 & Xa Pha & $3 / 186$ & 1.6 \\
9 & Pa Di & $4 / 186$ & 2.2 \\
10 & Kinh & $32 / 196$ & 17.2 \\
\hline
\end{tabular}

(Source: Provincial Department of Labor, Invalid and Social affairs, trafficking in women and children 2007-2008).

"You know, I have to serve 10 clients per day, maybe 15-20 clients in busy days or holidays. There are full kinds of clients. They sometimes request some strange modes. Some men claw during having sex, however, I have to please them". (A female sex worker in market of Ha Khau-China)

Restaurant owners often force sex workers to use drug. Therefore, almost sex workers are addicted to drugs. Thus, they are tied to be sex slaves to earn money to buy drugs. "Owners of the brothels usually entice sex workers to use drug, that's the way to tie sex workers to professionally commercial sex. Having no money to buy drug, they have to sell sex, and these kinds of sex workers seldom ask their customers to use condoms and risk of HIV/AIDS infection in this sex worker group is very high". (An officer of Lao Cai Social Evil prevention Department)

If sex workers over the border of Ha Khau district are infected with HIV, they were thrown back to Lao Cai. Due to unemployment and discrimination of the community, they still continued working as street prostitutes or sex workers without receiving healthcare and support of the local authority. That was considered as a source of HIV transmission in the community. "I was initially not permitted using condoms because I have to serve my owner's acquaintances. He told me to please his guests. After a period of time, I used condoms every act of sexual intercourse. However, my owners sent me for regular health check-up-HIV consultation like many others. If I was infected with HIV, he would send me back to Lao Cai like many other women working here. I do not know what they are doing in Lao Cai, when they are back, it is very difficult to get a job, you know". (A female sex worker at a guesthouse in $\mathrm{Ha} \mathrm{Khau}$ - China)

Lao Cai and Lang Son are provinces with mobile population and reported with high HIV prevalence. There were about 205 people infected with HIV/AIDS (2005) in Lao Cai, $41 \%$ of them are at the age of 13-29 years; $80 \%$ adolescent and youth in the total of 3265 people who are drug abuse victims. Lang Son has 2,219 HIV positive people. The age of HIV-infected people range from young to middle age groups but mainly among the working age, account for $80 \%$.

The study shows that there is a link between trafficking in women and girls, prostitution and HIV/AIDS. "Many returned victims were in difficult situation, jobless and discriminated, so they had difficulty in immigration when they come back to home, which makes them become street prostitutes or sex workers again or go to China since they were HIV infected. In Lao Cai city, there are some hot spots such as at Luong The Vinh street, Coc San commune, and the border gate areas. Many returned victims left for there to sell sex". (Chairwoman of Lao Cai Women's Union)

Many victims were abandoned by their families and suffered from stigma of the community. They are 
jobless, or have a unstable job with low income: $78.5 \%$ of them do agricultural work, lack of the capital for business development, lack of lifeskills and knowledge on safe migration. When returning to their localities, they are not in their families' registration records (resident is deleted from his/her family's resident record if he is absent for six months). Number of children returning along with their mothers have been not granted birth certificates.

The research team went to Kim Minh market (so called Vietnamese market) in Ha Khau. Through observation of goods sold in this market, we found that more than half of these goods are prohibited according to the list of forbidden goods of the Government of Viet Nam such as sex toys, aphrodisiacs, knives, swords, guns, and all are violent tools and sexually violent tools in specific.

"We have been selling goods here for a long time, Vietnamese women sell sex publicly in the second and third floors. There are about 500-600 of them. Out of those, there are some trafficked here and they are forced to sell sex, others volunteer to be sex workers. Among trafficked people, there are female adolescents. At first, they were allowed to take rest and provided with cosmetics, given aphrodisiacs daily and watched pornographic films. They were taught sexual techniques on how to serve clients and demonstrated by the owner. After one month, the owner stopped giving all allowances, so they voluntary became sex workers. Every day, they had about 10-20 clients.
Those newly trafficked women who did not accept to sell sex, would be left starving and beaten until they agree". (A female, saleswoman in the first floor)

Owners in these sex markets had to always find all means to have new sex workers to attract and maintain their operation, because new sex workers would help attract more clients, furthermore, each sex worker would work several months to one to two years then they would be moved to other places or escaped themselves. Because of the huge need for new sex workers, the crime of trafficking in women and children is increasing. In addition, women of more than 30 years old were trafficked to China to mainly be wives in families that they have a sex with many men in a family.

When being asked about the causes of trafficking in women and children, $44.7 \%$ of respondents said it is due to the poverty/difficult economic status, $34.2 \%$ wanted to have cushy and well paid jobs. Some of them mentioned causes related to psychology and awareness such as $37.7 \%$ trust seduction of acquaintance (in Lao Cai, it was said that there are about $50 \%$ of people who are easily trusting are trafficked); $40 \%$ were because those women and girls aped and were indulged (in Lao Cai, there are $40 \%$ of respondents), $23 \%$ were because they themselves were lack of knowledge on trafficking in persons. Other causes leading to the problem of women and girls being cheated and trafficked were mentioned such as unhappy families, domestic violence and divorced parents (Table 2).

Table 2 Causes of trafficking in women and girls.

\begin{tabular}{llll}
\hline \multirow{2}{*}{ Causes } & \multicolumn{1}{c}{ Provinces (\%) } & Average (\%) \\
\cline { 2 - 4 } Jobless/low income & Lang Son & Lao Cai & 20.1 \\
Desiring for a better life & 20.2 & 20.0 & 34.2 \\
Travel hobby & 33.0 & 33.5 & 28.1 \\
Trusting on enticement & 16.2 & 40.0 & 37.7 \\
Poverty, difficult economic condition & 25.3 & 50.0 & 44.7 \\
Unhappy family (domestic violence, divorce) & 45.5 & 44.0 & 23.1 \\
Non strict and loose social management & 31.3 & 15.0 & 1.5 \\
Lacking knowledge on this issue & 2.0 & 1.0 & 23.6 \\
Do not know & 14.1 & 33.0 & 5.0 \\
\hline
\end{tabular}


"All problems here are because of poverty, and jobless can lead to trafficking in women and girls. In my opinion, there should be jobs for these people, for instance factories, companies in these areas, because many of them are at working age, they need jobs. If not, they spend all free time for pleasure. People like me will not have anything to do if we don't find jobs ourselves; honestly, it is very difficult to find a job here. They mostly go for work in the South or in China; therefore, that problem is not preventable." (A female victim in Duyen Hai ward-Lao Cai city)

"Let me ask you a question that you are now poor and jobless, suddenly an acquaintance say a friend, or a relative come to introduce you to a job, go to work as a saleswoman in China, like we do in Viet Nam, but with monthly salary of 3-4 million Vietnam Dong, so they would go immediately! If we don't trust relatives, who else we would trust. Go! Go immediately. So what is it if it is not lack of knowledge?" (A young man in Lao Cai city)

In addition, there are causes related to adherence and implementation of policies, especially the problem of hotel management, especially HIV prevention in restaurants and hotels. There are not enough strong plans to prevent trafficking in women and girls crossing the border. There was no plan to effectively support repatriated women: health treatment, vocation, reintegration into the community.

There are ethnic minority factors in trafficking in women and girls: H'Mong women are easily tricked to be trafficked because there are still existing customs related to marriage such as catching wives, pulling wives, natural lifestyle in mountainous areas. Therefore, they lack of information on trafficking in persons, trafficking women and children and human rights.

"Hmong ethnic minority still maintains customs related to marriage such as pulling wives, robbing wives. These customs combined with low educational level, limited awareness on trafficking in persons making a part of women easily trust other people, with open attitude towards sex; therefore, traffickers take advantage to make friends and to promise of marriage, or to match make to others". (A cadre from Lao Cai Women's Union)

Almost all respondents said that traffickers are acquaintances, relatives or friends and others are strangers who look wealthy well-spoken.

"I went to China with my sister, who has been working there for a long time. At first, I did not know and then I understood. When we were out of money, I have to serve clients". (A female sex worker in Ha Khau - Van Nam province - China)

"Days ago, I heard of a girls studying in 10th grade who used to come my café. She likes a woman who had introduced herself to her that she was from Ha Noi. This woman is very pretty and well dressed. Whatever she said, that girl just obeyed because she was very well spoken". (A café attendant at a café in Duyen Hai ward, Lao Cai city)

Most respondents know some information on trafficking in women and girls, including causes and tricks of traffickers. However, when being asked about the relationship between trafficking in women, sexual violence and risk of HIV infection, most of them did not understand precisely including local authorities, mass organizations at commune/ward/town level. Many people said that they did not pay attention to and rarely receive information about this issue.

Among people who participated into the survey in the two provinces, it was found that cadres from Women's Union, Department of Social Evils Prevention, Policemen and border officers at provincial level had good knowledge on relationship between trafficking in women, sexual violence and risk of HIV infection. Following are some of their opinion:

"Trafficking in women and girls is increasing more and more, especially $60 \%-70 \%$ of total trafficked women are for commercial sex. They have been trafficked into brothels in China where they were forced to sell sex; virgin was forced to sell virginity. They become sexual slaves who initially should not use 
condoms when having sex with regular clients. They are at high risks of HIV infection". (Male, Lao Cai Social evil prevention Department)

"Many women from Lang Son and other district who were trafficked over the border to work in brothels, returned with sexually transmitted diseases. I know exactly some infected with HIV, but I cannot name. Because being trafficked to work as commercial sex workers and forced to sell sex a lot, they could not protect themselves from infected clients". (Female, Lang Son provincial Women's Union)

All women trafficked over the border to China were pushed into hotels, brothels to be sex workers for sexual exploitation and abuse. If any of them have HIV/AIDS, owners will force them to return to Vietnam. This can spread HIV transmission to the community because these victims came back home with no job so they had to sell sex in bars and streets in Lao Cai and Lang Son of Vietnam.

"People infected with HIV will be sent back with no jobs and they are discriminated by the community so they leave home to sell sex on the streets. We know some places where these women sell sex such as Coc San commune like in this city, Luong Khanh Thien Street, area near the border gate. We catch them in action some times. After having been told by their stories, we find out that we cannot solve these issues. In addition, there are many tourists and businessmen as well. They have their needs so we just let them go.
They do not use any condoms". (Lao Cai border officer).

In Table 3, consequences of trafficking in women and girls is significantly known: $37.2 \%$ said that it separated families; $29 \%$ said that they were isolated, unstable psychology; $28.6 \%$ said that they were forced to sell sex or to labor/affecting to their health, $27.6 \%$ said that they were ashamed and difficult to integrate into community. However, only $15.6 \%$ said that consequences of trafficking in women and children were contracting STDs and HIV/AIDS, 3.5\% said that there would have unwanted pregnancies.

There is obviously a close correlation between trafficking in women and girls for sexual exploitation and violence. However, when being asked, community people and victims are not sure about the risk of HIV infection among trafficked women and victims of sexual violence. "Women were trafficked for commercial sex likely have higher risk of infection". (A HIV infected victim)

Women who were trafficked for commercial sex are usually disrespected and despised, considered as filthy and debauched when they returned.

"I'm very gentle but I fight with them many times. My neighbors call me as a bad-mannered, ill-behaved woman, they even say that I am lascivious, dishonored, debauched, eloped with men so I should be in such punishment. In fact, I know who I am, I am deceived". (Female, a returned trafficked victim in That

Table 3 Consequences of trafficking in women and girls.

\begin{tabular}{llcc}
\hline \multirow{2}{*}{ Consequences } & \multicolumn{2}{c}{ Provinces } & Average (\%) \\
\cline { 2 - 4 } & Lang Son & Lao Cai & 23.6 \\
Reduction in physical health & 20.2 & 27.0 & 29.6 \\
Isolation and unstable psychiatrics & 23.2 & 36.0 & 23.6 \\
Physically abused, forced labor & 14.1 & 33.0 & 28.6 \\
Coercive sex & 22.2 & 35.0 & 15.6 \\
Sexual transmitted diseases & 9.1 & 22.0 & 3.5 \\
Unwanted pregnancy & 2.0 & 5.0 & 27.6 \\
Shamed, difficult in reintegration into community & 21.2 & 34.0 & 37.2 \\
Family separation & 36.4 & 38.0 & 19.6 \\
Financial shortage & 11.1 & 19.0 & 19.6 \\
Unsecured society & 20.2 & 19.0 & 8.0 \\
Do not know & 14.1 & 2.0 & \\
\hline
\end{tabular}


Khe town-Lang Son province)

Some repatriated women were isolated by their relatives and communities. They encountered many difficulties in their lives and finding jobs and no one has responsibilities to help them to initially stabilize their lives: "When I returned, no one believed me. I borrowed from relatives some money to do my business but they told me that they were afraid that I could not return them. Finally, I had to work far from here, where no one knows me. It was very irregular employment, there are some work today but not tomorrow. That is very strange! Why they do not think that if they were me, what they would do". (Female, a trafficked victim in Lao Cai city)

"I do not know what policy is available here, but I have not received any support. I was not allowed to take any loan nor having any health check-ups as you said. Because I escaped myself, I do not want any people knowing about my past". (Repatriated women in Lao Cai city)

"When I escaped back to Viet Nam, my parents took me to have an HIV test. My parents told me that it is to prevent from infection; they would support to treat if I had got that. But, you know, anyhow I was forced to have sex and I got disgrace. Whatever the results is, it is not important to me. If I go to get the result, which would show positive, the rest of my life will be like in hell". (A trafficked victim in Duyen Hai ward-Lao Cai city)

Viet Nam government has made great efforts to successfully realize its National Program on Combating trafficking in persons, called the Program 130. Viet Nam Government issued the Law on Gender Equality and the Law on Domestic Violence Prevention. Ministry of Justice of Viet Nam is developing Anti-human trafficking Law. It will be adopted by General Assembly soon [7, 8]. The Vietnamese Government signed an anti-trafficking memorandum of understanding with China and Cambodia for more cooperation in identifying victims and prosecuting traffickers. However, the fight against trafficking in persons is not effectively done because of the complexity of the phenomenon, global sex demand, increasing labor force and a great profit that sexual commerce brings about.

\section{Conclusion}

Trafficking in persons is a global, regional and national emerging problem. Combating trafficking in women and girls is a challenging mission $[9,10]$. To fight against the phenomenon, it needs a strong commitment, an inter-country cooperation and a comprehensive intervention investment in terms of strategies, policies, multi-stakeholders (authorities, police, justice, health providers and enforcement law and importantly, community participation). Educating on human rights, women human rights, gender equality and sexual health and safe sex behaviors and responsibilities will make a great contribution to fighting against sex trafficking and HIV/AIDS transmission. Promoting gender equality and women empowerment, victims support, poverty reduction, vulnerable group education and community participation need to be included in anti-trafficking strategies and plans of action of every governments at all levels. We have to emphasize anti trafficking in person not only government policies and programs but also the contribution of NGOs, civil society. These contributions are very important to prevent anti-trafficking to support victims and to enhance the awareness on human rights of community. In addition, the participation of community is crucial action because only the people know about the network of traffickers and who are the traffickers and who are in poverty and jobless. Therefore, raising awareness for community people on human rights and gender quality has great contribution to international and government policies on anti-trafficking in person.

\section{References}

[1] IOM. 2002. Combating Trafficking in South-East Asia-A Review of Policy and Programme Responses.

[2] Duc N. T. H. 2007. Institute for Reproductive and Family 
Health, Base Line Survey on Trafficking in Women and Girls and HIV/AIDS Transmission in Van Lang District, Lang Son Province.

[3] Duc N. T. H. 2006. Institute for Reproductive and Family Health, Assessment the Need if Mainstreaming anti HIV/AIDS into Trafficking in Women and Children Activities in Lang Son and Lao Cai Province, Supported by ICCO.

[4] Le B. D. 2005. Women Trafficking from Quang Ninh and through Quang Ninh to China, Supported by International Organization of Migration (IOM).

[5] Vu, T. H., and Vu, M. L. 2002. Research on Prevention of Trafficking in Women and Girls in Three Provinces of Quang Ninh, Thanh Hoa and Ho Chi Minh City, supported by ILO-IREC.

[6] Nguyen, T. H. D., and Pham, Q. N. 2002. The situation of Trafficking in women and girls in Mong Cai District.

[7] Vietnamese National Assembly, 2007, Law on Domestic Violence Prevention of Socialist Republic of Vietnam.

[8] Vietnamese Government. 2006. The Governmental program No. 130 on Trafficking in Women and Children.

[9] UNAIDS/UNIFEM/UNFPA. 2003. Women and HIV/AIDS Infection.

[10] United Nations General Assembly. 2000. UN Protocol on Human Trafficking Especially Women and Children, to Supplement to the UN Convention on Prevention of Inter-national Crimes. 